\title{
DETERMINATION OF 1/V-T (P, CONSTANT) DIAGRAMS OF HYDROGEN GASES BY GRAPH-ANALYTICAL METHODS
}

\author{
Beycan İbrahimoğlu*, Çiğdem Kanbeş Dindar ${ }^{2}$, Hazal Erol ${ }^{2}$, Salih Karasarı² \\ Keywords: Grapho-Analytical Method, Hydrogen, Ionization Temperature of Hydrogen
}

\begin{abstract}
Graph-analytical methods provide more accurate results in the analysis of $\mathrm{V}-\mathrm{T}$ ( $\mathrm{P}=$ constant) and $1 / \mathrm{V}-\mathrm{T}$ ( $\mathrm{P}=$ constant) diagrams of gases. In this study, as a continuation of $[1,2]^{*}$, the behavior of hydrogen gas was examined by using graph-analytical method under consideration of volume and density parameters at high pressure and temperature. In this paper, graph- analytical method was applied to draw and examine $\mathrm{V}-\mathrm{T}(\mathrm{P}=$ constant) and $1 / \mathrm{V}-\mathrm{P}(\mathrm{T}=\mathrm{constant})$ diagrams which were based on experimental data of hydrogen and other gases (Hydrogen, carbon dioxide, oxygen, argon, helium, neon, xenon and other gases) at high pressure and temperature. The results indicate that the behavior of hydrogen gas is different from the other gases.
\end{abstract}

\section{INTRODUCTION}

Data of the thermodynamic parameters (T,P) applied in process technology is determined by theoretical or experimental methods. Theoretical methods are not preferred in the industry. Therefore, values obtained with experimental methods are utilized. The parameters used in this study were obtained with experimental methods $[7,8]$. However, implementation of such experiments depends on major technical difficulties and financial expenditure. More effective and rapid testing methods used in the case of accelerated technical and scientific progress. One of the accepted methods is Graph- Analytical Method [1, 2, 4, 5, 6, 7].

Graph- Analytical Method is widely used in many fields such as physics, mathematics, astronomy, chemistry, crystallography etc. While the material is in gaseous form, it became possible to determine the basic points that exist in liquid and solid forms of the material, which is not possible by any experimental method, and information of thermodynamic parameters, system's equilibrium, phase transitions, phase diagrams, critical parameters $\left(\mathrm{T}_{\mathrm{cr}}, \mathrm{P}_{\mathrm{cr}}\right)$, melting, boiling and freezing points of the material by using Graph-Analytic Method [1, 2, $4,5,6,7]$.

\section{APPLICATION OF GRAPH-ANALYTICAL METHODS OF HYDROGEN GAS}

The results of previous studies [1,2] are shown that when graph-analytical methods are applied to gases, $\mathrm{V}-\mathrm{T}(\mathrm{P}=$ const. $)$ or $\mathrm{P}-\mathrm{T}(\mathrm{V}=$ const. $)$ isobars of the most gases intersect each other at a point on the $\mathrm{x}$-coordinate $(\mathrm{T}, \mathrm{K})$ and this temperature is the absolute zero point.

In the studies, it is discovered that in T $-\rho(\rho=1 / \mathrm{V})$ diagram of the hydrogen gas isobars do not intersect each other just like in $\mathrm{T}-\mathrm{V}$ diagram of the hydrogen and this was the difference of the hydrogen gas when compared to other gases.

It is possible to separate hydrogen graphics into two parts; values obtained from $\mathrm{P}=0.1$ to 10 bar pressure range and $\mathrm{P}=100$ to 1000 bar pressure range.

At low pressures $(\mathrm{P}=1-10$ bar, $\mathrm{P}=$ const.), isobars gathered at a point on the $\mathrm{x}$-coordinate $(\mathrm{T}, \mathrm{K})$ and this point was found to be $1820 \mathrm{~K}$ (Figure 2). Meanwhile, at high pressures $(\mathrm{P}=100-1000 \mathrm{bar}$ ), in T- $\rho$ diagram of the hydrogen gas isobars intersect each other at different points on the $\mathrm{x}$-axis for different pressure values (it is given in Figure 3 and Table 2). Increase of pressure reduces the amount of ionization and increases the ionization energy.

Differences observed in hydrogen gas when compared to other gases comes from the fact that its molecules have two modifications. At low temperatures, it is completely in para-modification form $\left(\mathrm{n}-\mathrm{H}_{2}\right)$. Meanwhile, with the rising temperature para-modification is partially balanced by transforming into orthohydrogen $\left(\mathrm{o}-\mathrm{H}_{2}\right)[9,11]$. Hydrogen concentration depends insignificantly on pressure and substantially on temperature. It is also known that para $\left(\mathrm{n}-\mathrm{H}_{2}\right)$ form transforms to ortho $\left(\mathrm{o}-\mathrm{H}_{2}\right)$ modification between $300 \mathrm{~K}$ and 
$500 \mathrm{~K}$. In our research, a discordance is observed when the temperature is between $350 \mathrm{~K}-500 \mathrm{~K}$ and the pressure is between $200 \mathrm{~atm}$ and $600 \mathrm{~atm}$. In
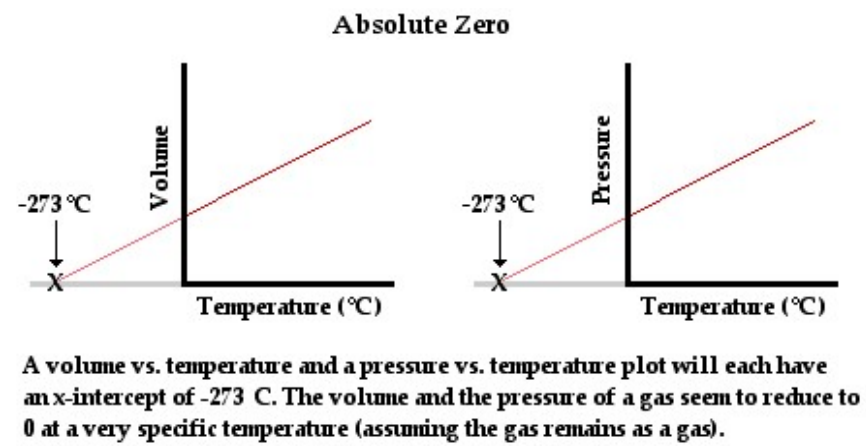
0 at a very specific temper ature (assuming the gas remains as a gas).

1.a.

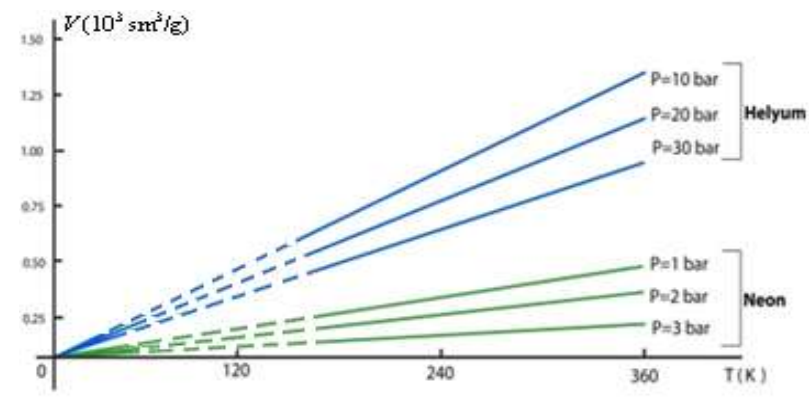

1.b.

Figure 1. In analogy to $T-V$ diagram also the $T-\rho(P=$ constant $)$ adherence of the gases is examined

the range of $(\mathrm{P}=1 ; \mathrm{P}=2 ; \mathrm{P}=4 ; \mathrm{P}=6 ; \mathrm{P}=8$ and $\mathrm{P}=10 \mathrm{bar})$ isobars of hydrogen gas gathered at a point $(\mathrm{T}=1820 \mathrm{~K})$ and this point indicates the point of ionization of hydrogen (Figure 2). Meanwhile, at high pressures $(\mathrm{P}=100-1000 \mathrm{bar}$, $\mathrm{P}=$ const.) intersection point of isobars with $\mathrm{T}$-axis, in accordance with the pressure, indicates the dissociative ionization temperature. Increase of pressure reduces the amount of dissociative ionization, but it increases the ionization energy. The ionization temperature of hydrogen varies in the literature $[9,10]$.

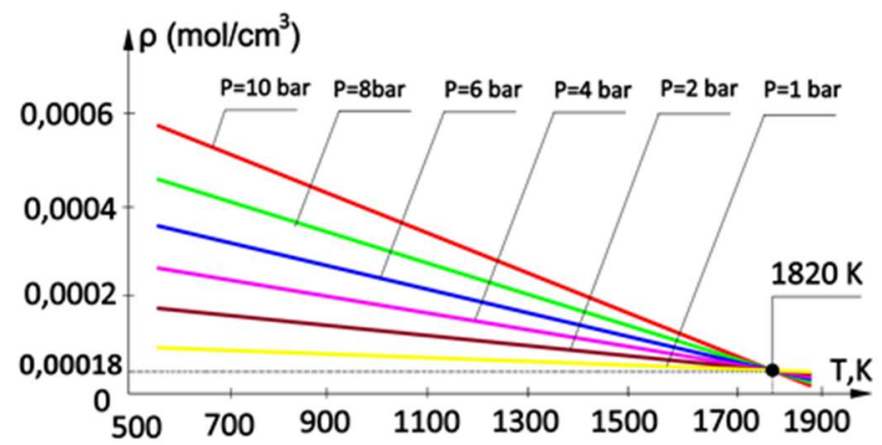

Figure 2. Graph of $\mathrm{T}-\rho(\mathrm{P}=$ const. $)$ for Hydrogen between $\mathrm{P}=1$ and $\mathrm{P}=10$ bar 


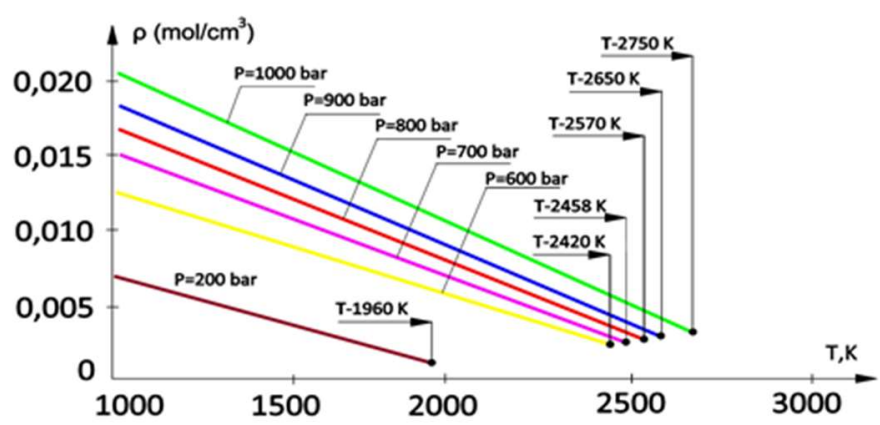

Figure 3. Graph of $\mathrm{T}-\rho(\mathrm{P}=$ const. $)$ for Hydrogen at the high pressure

Table 1. Isobars collection temperatures against pressure of hydrogen gas

\begin{tabular}{|l|l|}
\hline $\mathrm{P}=100$ bar & $\mathrm{T}=2100 \mathrm{~K}$ \\
\hline $\mathrm{P}=200$ bar & $\mathrm{T}=2140 \mathrm{~K}$ \\
\hline $\mathrm{P}=600$ bar & $\mathrm{T}=2420 \mathrm{~K}$ \\
\hline $\mathrm{P}=700$ bar & $\mathrm{T}=2458 \mathrm{~K}$ \\
\hline $\mathrm{P}=800$ bar & $\mathrm{T}=2570 \mathrm{~K}$ \\
\hline $\mathrm{P}=900$ bar & $\mathrm{T}=2658 \mathrm{~K}$ \\
\hline $\mathrm{P}=1000$ bar & $\mathrm{T}=2758 \mathrm{~K}$ \\
\hline
\end{tabular}

Table 2. The ionization temperature of hydrogen varies in the literature

\begin{tabular}{|c|c|c|c|c|c|c|}
\hline $\begin{array}{c}\text { Absolute } \\
\text { Tempe, K }\end{array}$ & 2000 & 2500 & 3000 & 3500 & 4000 & 5000 \\
\hline & 0,088 & 1,31 & 8,34 & 29, & 63,9 & 95,8 \\
Ionization & {$[10]$} & {$[10]$} & {$[10]$} & {$[10]$} & {$[10]$} & {$[10]$} \\
Ratio\% & 0,081 & 1,25 & 7,83 & 28,2 & 28,2 & 95,0 \\
& {$[9]$} & {$[9]$} & {$[9]$} & {$[9]$} & {$[9]$} & {$[9]$} \\
\hline
\end{tabular}

In the literature, dissociative ionization of hydrogen only depends on the temperature and these values are often contradictory. The energy released during the formation of the molecule determines the system stability. Therefore, thermal decomposition of hydrogen molecule occurs at high temperatures.

Graph-analytical methods have been applied to many gases $\left(\mathrm{H}_{2}, \mathrm{O}_{2}, \mathrm{CO}, \mathrm{CO}_{2}\right.$, Air, $\mathrm{Ne}, \mathrm{Xe}, \mathrm{N}_{2}$, Ar, etc.) and $\mathrm{T}-\rho(\mathrm{P}=$ const. $)$ dependence was plotted using the reported data in $[7,8]$.

Examinations of $\mathrm{T}-\rho(\mathrm{P}=$ const. $)$ diagram has shown that all isobars intersect at one point on the T-axis in the direction of rising temperature. The results of linear extrapolation performed on many gases have demonstrated that this point of gathering of all isobars coincides with the starting point of dissociative ionization process.

It was observed that isobar points gathered in accordance to ionization point of each gas on the $\mathrm{T}$ axis. Because each gas has different ionization energy.

As well known that $\mathrm{V}-\mathrm{T}(\mathrm{P}=$ const. $)$ or $\mathrm{P}-\mathrm{T}(\mathrm{V}=$ const. $)$ isobars gathered at one point on $\mathrm{T}$ axis and this point is one of the basic points of materials and it is known as the absolute temperature. Using the same analogy on $\mathrm{T}-\rho(\mathrm{P}=$ constant $)$ graph, the intersection point of isobars indicates the presence of another basic point. Careful investigations indicate that this point is different for each gas and it corresponds to ionization temperature of the gases.

For example, in $\mathrm{T}-\rho(\mathrm{P}=$ constant $)$ graph of the oxygen, all isobars intersect at $2550 \mathrm{~K}$ (Table 1). Data used for oxygen gas is taken from $[7,8]$ up to $1300 \mathrm{~K}$, rest of the data is obtained by extrapolation. In the literature ionization temperature of the oxygen is given as $2573 \mathrm{~K} \mathrm{[10]} \mathrm{and} \mathrm{it} \mathrm{is} \mathrm{found} \mathrm{as} 2550 \mathrm{~K}$ by using graph-analytic method. The ionization temperature for various gases are given in Table 3. First column gives the ionization temperatures obtained by Graph-Analytic Method and the second column gives the ionization temperatures from the literature. 
Table 3. Data of gas are observed from literature and graphic

\begin{tabular}{|c|c|c|c|}
\hline No & Gas & $\begin{array}{c}\text { The Data using Graph- } \\
\text { Analytic Method, } \\
\text { Temperature, K }\end{array}$ & $\begin{array}{c}\text { Literature, } \\
\text { Temperature, } \\
\text { K }\end{array}$ \\
\hline 1 & Oxygen & $2550 \mathrm{~K}$ & $2573 \mathrm{~K}[12]$ \\
\hline 2 & Argon & $2920 \mathrm{~K}$ & - \\
\hline 3 & Air & $2690 \mathrm{~K}$ & - \\
\hline 4 & Nitrogen & $3700 \mathrm{~K}$ & $3573 \mathrm{~K}[19]$ \\
\hline 5 & Fluor & $3000 \mathrm{~K}$ & - \\
\hline 6 & $\begin{array}{c}\text { Carbon } \\
\text { Dioxide }\end{array}$ & $2023 \mathrm{~K}$ & $2273 \mathrm{~K}[19]$ \\
\hline
\end{tabular}

\section{RESULTS AND DISCUSSIONS}

The Graph-Analytic method helps with highlighting physical processes, simplifying the comprehension of occurrences, abstract thinking, perception, analyzing and comparison, and finding better solutions for problems. By identifying unknown values of a matter using Graph-Analytic method, it is possible to obtain broader knowledge on fundamental points and thermodynamic parameters of a matter's liquid and solid form in its gaseous state. This method is widely used in many fields such as physics, mathematics, astronomy, chemistry, etc.

By implementing the graph-analytic method on the data of isobaric and isochoric processes at a certain temperature of the matter in a gaseous state, existence of the fundamental point of its solid form has been discovered. Therefore, in the literature provided [1,2], by implementing the Graph-Analytic method on P-T and VT diagrams of $\mathrm{O}_{2}, \mathrm{CO}, \mathrm{CO}_{2}, \mathrm{CH}_{4}, \mathrm{Ar}, \mathrm{He}, \mathrm{H}_{2}$ and other gases, an intersection at $\mathrm{T}=-273^{\circ} \mathrm{C}$ was determined.

In this study, $1 / \mathrm{V}-\mathrm{T}$ (P, constant) diagram of all the gases was examined using Graph-analytic method. For gases, there are two types of ionization: thermal and electrical ionization. Thermal ionization occurs via heating of gas and as a result of the following actions: Gas converts into free radicals, ions and other particles due to heat, electrical field etc. and it changes to a new phase. Ionization of gas begins with degradation of chemical bonds of atoms or molecules. The energy required to break a single molecule off is called dissociation energy and this energy is different for each material. The dissociation energy characterizes the chemical bond strength of the material. Gases dissociated at the high temperature and this process is called thermal decomposition. If an atom loses one or more electrons, any energy level acquires charge or charges and this process is called ionization. Dissociation reaction occurs via a lot gas formation.

The degree of dissociation increases quickly with the raising temperature depending on the pressure. In gases dissociation energy depends on degree of freedom of gas atoms.

- Degree of freedom for monoatomic gas $\quad \mathrm{i}=3$

- Degree of freedom for diatomic gas $\quad \mathrm{i}=5$

- Degree of freedom for polyatomic gas $\quad \mathrm{i}=6$

From the properties of material phases it is known that liquids have translational order, meanwhile crystal solids have translational and orientation order. However, gas atoms have disordered structure. In plasmas and gas, the atoms are in free state. Accordingly, a material in gas or plasma form has a single thermodynamic-phase. Degree of freedom and complex action of atoms in gas phase differ from solid and liquid phases.

There are no active forces that keep the gas atoms together. Meanwhile, solid and liquid atoms are under influence of ionic, metallic, covalent or Van der Waals bonds and that is the main difference from the gases. Since, atom in a material in gas phase are governed by law of quantum mechanics, law of classic mechanics cannot be used to explain these differences observed in gases.

It is obvious that atoms are microscopic particles and they have very small weight, and they consist of positively charged core and negatively charged electrons $[17,18]$. These differences of the gas atoms, compared to solid and liquid atoms lead to a possibility of carrying information about the material and its basic points. At the same time, this point could be defined as the ionized state of monatomic gases and a matter's transition to the plasma state in modern physics and chemistry.

98\% of our universe consists of Plasma, the 4th state of a matter, is formed as a result of gaseous matter going through ionization process and is the main reason of our universe's existence. Species that create Plasma 
combine the principals of physics, matter and energy. It is the natural form of a matter at a high temperature and is a dynamic system. At the same time, it is used in the application of electromagnetic forces.

Accurate methods are being designed for the technological processes and experiments performed under high pressure and temperature. Theoretic and empirical data is used for these methods. However, theoretic method can sometimes have incorrect results and empirical method is complicated and costly. Graph-Analytic method can be a potential substitute to these methods. Furthermore, Graph-Analytic method provides a broader information on thermodynamic (freezing and boiling points) and critical (Tcr, Pcr) parameters under high pressure and temperature.

Absolute temperature and ionization point for argon gas are shown on the $\mathrm{T}$ axis of $\mathrm{V}-\mathrm{T},(\mathrm{P}=$ const.) and $\rho-\mathrm{T}$, $(\mathrm{P}=$ const.) diagrams obtained using graph - analytical method (Figure 4$)$. At the same time, phase changes of argon and hydrogen gas are shown Figure 5 and Figure 6.

1/V-T (P, constant) diagram of all gases have demonstrated that all isobars intersect at one point on the $\mathrm{T}$-axis $(\mathrm{T}, \mathrm{K})$ such as argon isobars intersects at $\sim 2950 \mathrm{~K}$ and oxygen isobars at $\sim 2550 \mathrm{~K}$. Meanwhile, hydrogen isobars behave different compared to other gases at high pressure in which its isobars intersect each other at different points on the $\mathrm{x}$-axis for different pressure values.

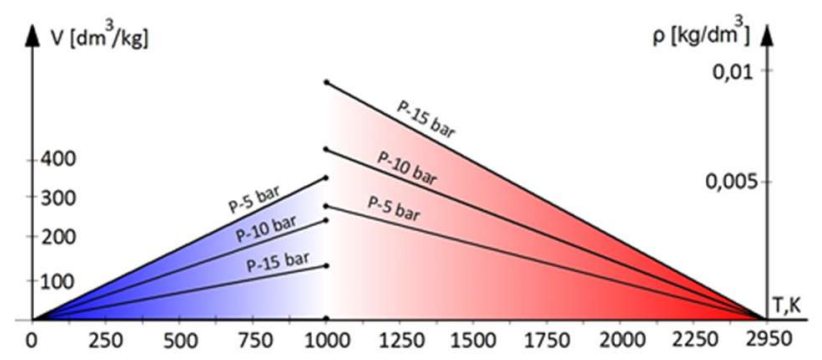

Figure 4. Graph of $\mathrm{V}-\mathrm{T},(\mathrm{P}=$ const. $)$ and $\rho-\mathrm{T},(\mathrm{P}=$ const. $)$ relationship for Argon

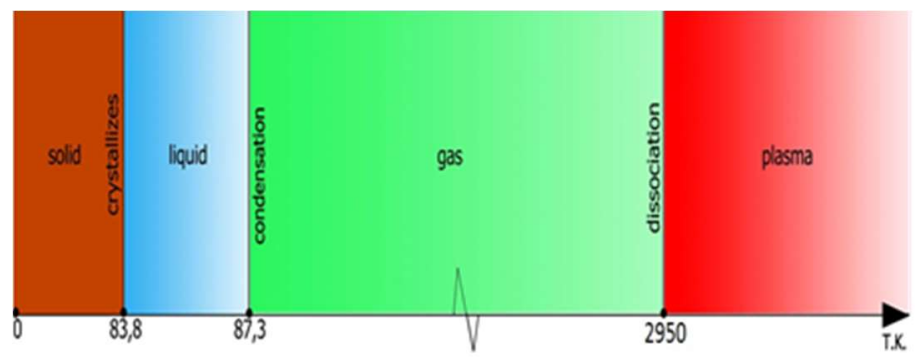

Figure 5. Phase changing temperature for gas of Argon

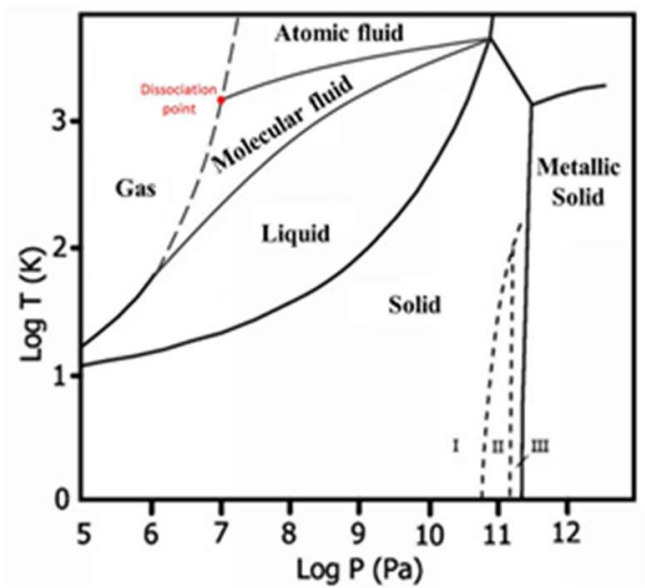

Figure 6. Phase diagram of Hydrogen gas has been developed considering graph-analytic method and studies on $[13,14,15,16]$ 
Differences are observed in hydrogen gas when compared to other gases and these differences arise from the fact that its molecules have two modified forms. Two forms show the same chemical properties. However, they have different physical properties due to an orbit difference. At low temperatures, hydrogen is completely in para-modification form $\left(n-H_{2}\right)$, with the rising temperature para-modification is partially balanced by transforming into ortho-hydrogen $\left(\mathrm{o}-\mathrm{H}_{2}\right)$. The thermal energy released during conversion It shows the released heat difference with the increase of pressure. Therefore, it is thought that hydrogen behaves differently to other gases under high pressure.

\section{CONCLUSIONS}

The results indicate that Graph-Analytical methods could be utilized to determine the intersection points of the isobars of the gases on 1/V-T (P, constant) diagrams T-axis. Also, it provides the ability to elaborate whether the intersection points are disassociation or ionization temperatures or the temperature where the transition to plasma is formed.

According to our studies, it is thought that the point shows the dissociative ionization temperature for all gases.

\section{NOMENCLATURE}

\section{Symbols}

$\mathrm{P} \quad$ Pressure $(\mathrm{Pa})$

V Volume $\left(\mathrm{dm}^{3}\right)$

$\mathrm{T}$ Temperature (K)

$\rho$ Density $\left(\mathrm{kg} / \mathrm{dm}^{3}\right), 1 / \mathrm{V}=\rho$

$\mathrm{T}_{\mathrm{cr}} \quad$ Critical temperature (K)

$\mathrm{P}_{\mathrm{cr}} \quad$ Critical pressure

\section{REFERENCES}

[1] İbrahimoğlu, B., Veziroğlu, N., Hüseynov A., 2005, "Study of Thermodynamic Parameters of Hydrogen Gas by Grapho-Analytic Method”, International Journal of Hydrogen Energy, 30, 515-519.

[2] İbrahimoğlu, B., Veziroğlu, N., Hüseynov A., Schur, D., 2004, "Study of Thermodynamic Parameters of Hydrogen Gas by Graph-Analytic-Method", Hydrogen Materials Science and Chemistry of Carbon Nanomaterials 225-232.

[3] Hüseynov A., İbrahimoğlu, B., "Phase Equilibrium and Metastability of Liquid Benzene at High Pressures", The Journal of Chemical Physics 124(20):204505 (2006) PMID 16774351.

[4]İbrahimoğlu, B., Rehimov, A. "Determination of Experimental Pressure and Temperature Dates of Liquids by Mathematical Methods”, Journal of Engineering Physics 19, No: 3, 1985, p. 498, Moscow.

[5]İbrahimoğlu, B., Naziyev, Y.M., Aliyev, F.N.,1992," Contribution to the Scientific and Technical Congress on Heat Processes", Baku, Azerbaijan, (unpublished).

[6]İbrahimoğlu, B., Aliyev, F.N.,1986," Contribution to the Scientific and Technical Congress on Heat Processes”, Baku, Azerbaijan, (unpublished).

[7] İbrahimoğlu B., Guseynov A.F., Alibeyli R.,2005, “Contribution to the Ninth International Conference on Hydrogen Materials Science and Chemistry of Carbon Nanomaterials" Sevastopol, Ukraine, (unpublished).

[8] İbrahimoğlu B., Guseynov A.F., Alibeyli R.,2005, “Contribution to the Ninth International Conference on Hydrogen Materials Science and Chemistry of Carbon Nanomaterials" Sevastopol, Ukraine, (unpublished).

[9]Vargaftik, N.B., 1975, "Handbook of Thermal Conductivity of Liquids and Gases", 1st Edition, Springer-Verlag Berlin Heidelberg.

[10] Kreith, F., 2000," CRC Handbook of Thermal Engineering", CRC Press, London.

[11] Langmuir, I., 1925,"Flames of Atomic Hydrogen" "Science," New Series, Vol. 62, No. 1612, November 20.

[12] Krugosvet Ansiklopedisi, Part: Oxygen, 24.cilt, 2000.

[13] Wigneг E., Huntington H. B.,1935, “On the Possibility of a Metallic Modification of Hydrogen”, "J. Chem. Phys." v. 3, p. 746.

[14] Wigne г E., Huntington H. B.,1935, On the Possibility of a Metallic Modification of Hydrogen, "J. Chem. Phys.", 1935, v. 3, p. 746.

[15] Kagan Yu., Pushkarev V., Kholas A., 1977,” Zh. Eksp. ,Teor. Fiz. 73:967. [Soviet Phys. -JETP 46, 511].

[16] V. Zobnina, 2011, “Karbon Monoksit Zehirlenmesi”, Irkutsk Devlet T1p Üniversitesi - St Petersburg,86. 
Journal of Thermal Engineering, Research Article, Vol. 3, No. 1, pp. 1071-1077, January, 2017

[17] Fiziksel Ansiklopedik Sözlük./Ch. Ed. Prokhorov.- M: Sov.. Ansiklopedi 1984.

[18] Büyük Rus Ansiklopedisi,1988, 36-944.

[19] Tadjiev K., Kumarov R.Y., Arkhipov V.B., Sharipov E.R., Safayev M.O., Safayev M.M., Salimov N.P., Mukhamedzhanov S.Y., 2005, "Removal of Flue Gas Cleaning and Disposal of Industrial Wastes, (К вопросу очистки дымовых газов от диоксида углерода из промышленных выбросов и его утилизация)”. 